\title{
Prescription and Cost Consideration at a Diabetic Clinic in Ibadan, Nigeria: A Report
}

\author{
Enwere $^{1}$ OO, Salako, BL and Falade ${ }^{1,3} \mathrm{CO}$ \\ ${ }^{1}$ Department of Clinical Pharmacology, ${ }^{2}$ Department of Medicine, University College \\ Hospital, Ibadan, Nigeria ${ }^{3}$ Department of Pharmacology and Therapeutics, College of \\ Medicine, University of Ibadan, Nigeria
}

\section{SUMMARY}

Diabetes mellitus is associated with high morbidity and mortality. The high cost of treatment is a major concern to both physicians and patients. This study assessed pattern and cost of drugs prescribed at a diabetic clinic, and identified the commonest reasons militating against adherence to therapy.The study was a cross-sectional survey. Data was obtained from all prescriptions issued following each day's consultation. Patients were also interviewed using a self-administered questionnaire. Means were compared using $t$-test and chi $^{2}$ was used to test associations. $P$-value $<0.05$ was considered significant statistically. Three hundred and fortynine (349) diabetic patients were seen. There were more females than males $(61.9 \%$ \& $38.1 \%)$. About 36\% (125) of the patients had no formal education and $12 \%$ (42) had only primary education, while $80 \%$ were from the low socioeconomic class. The average number of drugs prescribed/day was 4 with an average cost of medications/day being N183.5 \pm 150.4 (Nigerian naira) approx $\$ 1.40$ (USD). The commonest reasons that militate against adherence to prescribed drugs were the high cost of the drugs (52.2\%) and the large number of drugs to be taken (43.5\%). Biguanides $(66 \%)$ are the commonest oral hypoglycemic agents prescribed, while ACEIs (53\%) were the commonest antihypertensive prescribed. Only $5.4 \%$ of patients received statins. The cost of medications prescribed to diabetic patients in Ibadan, Nigeria

\section{All Correspondence to Dr O. O. Enwere}

Department of Clinical Pharmacology, University College Hospital, PMB 5116, Ibadan, Oyo State, Nigeria.

E-mail: okeyzie@yahoo.com

Tel: 234-0803-3260826

Annals of Ibadan Postgraduate Medicine. Vol.4 №2 Dec.,2006 is quite high. Every effort at cost reduction through improved prescription of drugs as generics and rational prescribing is necessary so as to encourage adherence to drug therapy.

Key words: Cost of drugs, diabetes mellitus, drug use indicators, Nigeria, factors

\section{INTRODUCTION}

Diabetes mellitus is a major non-communicable disease with a higher incidence in the developed countries[1]. However, there is demonstrable evidence to show that the incidence is rising in developing countries with prevalence estimates in Africa of $1 \%$ in rural areas and 5-7\% in urban subSaharan Africa, while estimates of up to $13 \%$ has been reported in more developed areas in South Africa and Indian populations[2, 3, 4,5]. The burden of diabetes mellitus in Nigeria is similar to what has been observed in other parts of sub-Saharan Africa. The prevalence of diabetes mellitus varies between $1 \%$ and $8 \%$ depending on the area of the country that is surveyed[6, 7, 8, 9].

While recognizing the need to treat diabetes mellitus in a developing country like Nigeria using drugs with proven efficacy based on best evidence, the prevailing social, cultural and economic environment of individual patients must be considered. Most patients with diabetes in Nigeria have little or no formal education and are poor with little understanding of the nature of their disease[ 10 , 11]. Additionally, scarcity of health resources, prohibitive cost of drugs or their non-availability, sale of fake drugs and the easy access to the traditional and faith healers militate against the optimal management of a chronic disease like diabetes 
mellitus[12]. The care of diabetes is expensive compared to management of other chronic illnesses. In the United States, the per capita annual costs of health care for people with diabetes rose from $\$ 10,071$ in 1997 to $\$ 13,243$ in 2002, an increase of more than $30 \%$, while health care costs for people without diabetes amounted to $\$ 2,560$ in 2002; with the total annual economic cost of diabetes in 2002 estimated to be $\$ 132$ billion[13]. A direct cost estimate of the treatment of diabetes in Nigeria is necessary in the context of the large indigent diabetic population. Provision of drugs in their generic names and rational prescription of drugs are recognized measures that can considerably reduce cost of drugs to patients without a fall in treatment standards towards attaining optimal diabetic control.

This study aims at assessing the pattern of drug prescription using some World Health Organization (WHO) drug use indicators, including the daily cost of medications to patients as well as identifying the commonest reasons militating against adherence to drugs therapy.

\section{MATERIALS AND METHODS}

The study was carried out at the Medical Outpatient Clinic (MOP) of the University College Hospital (a 850-bed tertiary care hospital), Ibadan, Nigeria. Ibadan is the largest indigenous town in Africa, south of the Sahara and it is located in south-western Nigeria, 125 kilometers from Lagos. It has a calculated population of $3,800,000$, while the Yoruba comprise its principal inhabitants.

Ethical approval for the study was obtained from the University of Ibadan/University College Hospital Joint Institution Review Committee (UI/ UCH JIRC).

Seven specialty clinics in internal medicine are run in the MOP weekly including endocrinology where most patients with diabetes mellitus are seen in addition to other medical conditions including thyrotoxicosis, hypertension, etc.

The study was part of a larger cross-sectional survey over an eight (8) working week period between December 2004 and February 2005. The endocrinology clinic is held once a week on Monday mornings. All prescriptions issued to patients attending the endocrinology clinic during this period immediately following each day's consultation at the MOP were copied out from the case files and recorded on specially designed case record forms. Prescriptions obtained were used to characterize the prescribing patterns at the clinics by applying some WHO Drug Use Indicators[14]. WHO drug use indicators assessed were the average number of drugs prescribed per encounter, percentage of drugs prescribed by generic name, percentage of drugs prescribed from hospital essential drug list and formulary and average cost of drugs per encounter. The percentage of drugs prescribed from the hospital essential drug list was determined using the third edition of the hospital Essential Drug List and Formulary (2003)[15]. A pharmacist in the hospital pharmacy using the current hospital drug-pricing list calculated the cost of the prescribed drugs. Prescriptions of patients with serious medical conditions requiring subsequent hospital admission were excluded. Intravenous fluids and blood transfusions were also not regarded as prescribed drugs for the purpose of this study. All improperly or incompletely written prescriptions were noted but excluded from the final analysis.

Patients to be seen at the MOP during the study period were interviewed just before consultation commenced to assess the commonest reasons for non-adherence to medical therapy using a self-administered questionnaire or investigator assisted in the case of illiterate patients.

According to the World Health Organization document on 'How to investigate drug use in Health facilities' (1993), a minimum of 100 prescriptions per clinic is expected to give a $95 \%$ confidence interval of within $10 \%$ for the individual result[16]. All data were entered into SPSS 10.0 for windows. In the statistical analysis, frequencies, mean values and percentages were presented. Comparison of means was done using t-test and chi square used to compare variables. A $P$ value $<0.05$ was considered statistically significant.

\section{RESULTS}

A total of 354 patients were seen at the endocrinology clinic during the study period. Three hundred and forty nine $(98.6 \%)$ of the patients had diabetes mellitus with or without hypertension, while $3(0.8 \%)$ had thyrotoxicosis and $2(0.6 \%)$ had pulmonary tuberculosis. Only prescriptions of those with diabetes mellitus were included in the analysis. Three hundred and twenty three $(92.6 \%)$ of the 
patients were seen on follow-up basis while only twenty six (7.4\%) of the patients were new cases. Females with diabetes mellitus were $216(61.9 \%)$ while the males were 133 (38.1\%). Both sexes were similarly matched for age (Average age of $57.8 \mathrm{yrs}$ \pm 12 for females with a range of 21-81yrs; and $57.2 \mathrm{yrs} \pm 15$ for males with a range of $16-82 \mathrm{yrs}$; $\mathrm{P}=0.67,95 \% \mathrm{CI}-3.4,2.2)$. Table 1 shows details of level of education and occupational distribution of patients.

TABLE 1: Educational and occupational distribution of patients seen at the diabetic clinic

\begin{tabular}{lll}
\hline $\begin{array}{l}\text { Demographic } \\
\text { characteristics }\end{array}$ & \multicolumn{1}{c}{$\begin{array}{c}\text { Number of patients } \\
(\%)\end{array}$} \\
\hline Education level & None & $\begin{array}{l}125(35.8 \%) \\
\end{array}$ \\
& Primary/Islamic & $42(12 \%)$ \\
& Secondary & $70(20 \%)$ \\
& Tertiary & $112(32.1 \%)$ \\
& Total & $349(100 \%)$ \\
Occupation & Petty traders & $195(56 \%)$ \\
& Retired workers & $56(16)$ \\
& Business/ & $28(8 \%)$ \\
& Professionals & \\
& Students & $28(8 \%)$ \\
& Farmers & $14(4 \%)$ \\
& Civil servants & $14(4 \%)$ \\
& Unemployed & $14(4 \%)$ \\
& Total & $349(100 \%)$ \\
\hline
\end{tabular}

Analysis of the prescription pattern using some World Health Organization (WHO) core drug use indicators shows that the average number of drugs prescribed/day at the diabetic clinic is 4; percentage of drugs prescribed in their generic name is $47.5 \%$ \pm 27.6 ; percentage of drugs prescribed from the hospital essential drug list (EDL) is $98.6 \% \pm 5.6$; and the mean and median daily cost of medications to the patients are N183.5 \pm 150.4 and N 156 (Nigerian Naira), approx \$1.42 and \$1.2 (USD) respectively.

However, $35 \%$ of female patients were prescribed less than 4 drugs as compared to $28 \%$ of their male counterparts ( $\tilde{n}=0.147$; OR 1.4; $95 \%$ CI $0.9,2.3$ ) despite the fact that $52 \%$ of both sexes had only diabetes mellitus as a single diagnosis $(\mathrm{P}=0.94$; OR 0.98; 95\% CI 0.6, 1.5).

Two hundred and twenty five (225) patients consented to answer the study questionnaire. The commonest complaint and reason for non-adherence to therapy given by the follow-up patients is the high cost of the drugs (52.2\%). While $43.5 \%$ thought that the large number of drugs to be taken discourages adherence to therapy; only $13 \%$ of follow-up patients attributed non-adherence to therapy to the side effects of the drugs.

Table 2 shows the percentage of diabetic patients prescribed various drugs during the study period. Biguanides $(65.9 \%)$ were the most often prescribed hypoglycemic agents while $26.4 \%$ of patients received insulin. Angiotensin Converting Enzyme Inhibitors or Angiotensin Receptor Blockers (ACEI/ARBs) $(52.7 \%)$ were the most often prescribed antihypertensive drugs in patients who also had high blood pressure. Antiplatelets (Aspirin $75-150 \mathrm{mg}$ ) were prescribed to $56.4 \%$ of the patients while only $5.4 \%$ of patients had statins prescribed.

TABLE 2: Percentage distribution of patients prescribed various drugs at the diabetic clinic

\begin{tabular}{|c|c|c|}
\hline & Drug types & $\begin{array}{c}\text { Number of } \\
\text { patients } \\
(\mathrm{N}=349) \\
(\%)\end{array}$ \\
\hline $\begin{array}{l}\text { Antidiabetics } \\
\text { agents }\end{array}$ & $\begin{array}{l}\text { Biguanides } \\
\text { Sulphonylureas } \\
\text { Insulin }\end{array}$ & $\begin{array}{l}230(65.9 \%) \\
189(54.2 \%) \\
92(26.4 \%)\end{array}$ \\
\hline Antihypertensives & $\begin{array}{l}\text { ACEI/ARBs } \\
\text { Calcium } \\
\text { antagonists } \\
\text { Alpha methyldopa } \\
\text { Diuretics } \\
\text { â-blockers }\end{array}$ & $\begin{array}{l}184(52.7 \%) \\
\\
128(36.7 \%) \\
36(10.3 \%) \\
24(6.9 \%) \\
5(1.4 \%)\end{array}$ \\
\hline Others & $\begin{array}{l}\text { Antiplatelets } \\
\text { Statins }\end{array}$ & $\begin{array}{l}197(56.4 \%) \\
19(5.4 \%)\end{array}$ \\
\hline
\end{tabular}

\section{DISCUSSION}

Diabetes mellitus is a potentially devastating disease associated with increased morbidity and mortality. Many studies have demonstrated the need to 
prevent complications not just with tight glycaemic control, but also control of other factors associated with increased risk of cardiovascular complications like blood pressure and cholesterol levels [17, 18]. A high proportion of the patients are women. In south west Nigeria, obesity and insulin resistance, risk factors for diabetes mellitus are commoner in women [19]. Most diabetic patients in this part of the country are from the uninformed/ignorant population as reflected by the high proportion of patients with little or no education. Also a large proportion of these patients are from the low socioeconomic class comprising either petty traders, retired workers, farmers or the unemployed. This implies that resources available to most of these patients are small and a factor to be considered when drugs are prescribed.

The high average number of drugs prescribed to patients with diabetes is not surprising. It is recognized that patients with diabetes mellitus are generally prescribed more drugs than other patients [20]. Additionally, the low prescription of drugs in their generic names contributes to the high mean cost of drugs/day to patients with diabetes mellitus. At N183.5 (Naira)/ day approx $\$ 1.42$ (USD)/ day, it is unlikely that most of the patients will be able to sustain their supply of drugs and therefore the adherence to therapy. Nigeria's per capita income at 2005 of $\$ 560$ (USD) [21] reflects the low spending power of the population. The high cost of medications and the large number of prescribed drugs were the common reasons given by patients for non-adherence to prescribed drugs. This further emphasizes the need to reduce the cost of medications to patients through increased prescription of drugs in their generic names and rational drug prescription without a fall in treatment standards. Oral hypoglycemic agents (OHAs) are the commonly prescribed antidiabetic agents. The endocrinology clinic caters for adults who largely have Type 2 diabetes mellitus and require oral agents for blood glucose control most times. Alebiosu (2004) also noted a similarly high prescription of OHAs in Sagamu [22] in another study in Southwestern Nigeria. However a higher percentage of patients in Ibadan are prescribed insulin compared to the Sagamu study. Also, the ACE inhibitors are the commonest antihypertensive drugs prescribed.
The role of ACE inhibitors in the reduction of cardiovascular associated morbidity and mortality is established [22]. The human insulin, ACEIs and statins are expensive, many of which still exist in their brand names. However, use of ACE inhibitors and statins preferably in their cheaper generic forms where available should be prescribed for all diabetes patients. Perhaps introduction of "polypills" will also reduce the cost and number of drugs while maintaining treatment goals. The polypill is a type of drug that would contain medications to lower cholesterol and blood pressure, aspirin as anticlotting agent, and folic acid to help prevent atherosclerosis all combined in a tablet.

Calcium antagonists are used more often in Ibadan compared to Sagamu where alpha-blockers and centrally acting drugs are the commonly prescribed antihypertensive drug.

The lipid lowering agents (statins) were prescribed only to a small proportion of patients. Evidence now exists about the benefit of statins in reducing cardiovascular events in diabetic patients independent of lipid levels [23, 24]. However, the high cost of these drugs may limit their prescription in our diabetic population where the emphasis is on adequate blood pressure and blood glucose control.

\section{CONCLUSION}

This study shows that most patients attending the diabetic clinic in UCH Ibadan are mainly from the low socio-economic class. The cost of daily medications to patients is expectedly high due to the high number of drugs prescribed and the low percentage of drugs prescribed in their generic names. The cost of drugs is the commonest reason given by patients militating against adherence to therapy. The prescription of ACEIs is commendable but can be improved.

\section{REFERENCES}

1. World Health Organization. Diabetes mellitus: Report of a WHO Study Group. Geneva: World Health Organization, 1985

2. Motala AA, Omar MA and Pirie FJ. Diabetes in Africa: epidemiology of type 1 and type 2 diabetes in Africa. J Cardiovasc Risk. 2003; 10: 77- 83. 
3. Sobngwi E, Mauyais-Javis F, Vexiau P, Mbanya JC and Gautier JF. Diabetes in Africas, I: epidemiology and clinical specificities. Diabetes Metab. 2001; 27: 628-634.

4. Amoah AGB, Owusu SK and Adjei S. Diabetes in Ghana: a community based prevalence study in Greater Accra. Diabetes Res Clin Pract. 2002; 56: 197-205.

5. Cooper RS, Rotimi CN, Kaufman JS, Owoaje EE, Fraser H, Forrester T, Wilks R, Riste LK and Cruickshank JK. Prevalence of NIDDM among populations of the African diaspora. Diabetes Care. 1997; 20(3): 343-8

6. Ohwovoriole AE, Kuti JA and Kabiawu SI. Casual blood glucose levels and prevalence of undiscovered diabetes mellitus in Lagos Metropolis Nigerians. Diabetes Res Clin Pract 1988 Jan 7; 4(2): 153-8

7. Owoaje EE, Rotimi CN, Kaufman JS, Tracy $\mathrm{J}$ and Cooper RS. Prevalence of adult diabetes in Ibadan, Nigeria. East Afr Med J. 1997; 74(5): 299302

8. Rotimi CN, Cooper RS, Okosun IS, Olatunbosun ST, Bella AF, Wilks R, Bennett F, Cruickshank JK and Forrester TE. Prevalence of diabetes and impaired glucose tolerance in Nigerians, Jamaicans and US blacks. Ethn Dis. 1999; 9(2): 190-200

9. Nyenwe EA, Odia OJ, Ihekwaba AE, Ojule A and Babatunde S. Type 2 diabetes in adult Nigerians: a study of its prevalence and risk factors in Port Harcourt, Nigeria. Diabetes Res Clin Pract. 2003 Dec; 62(3): 177-85

10. Adetuyibi A. Diabetes in the Nigerian African. III. Socioeconomic aspects. Trop Geogr Med. 1976 Sep; 28(3): 165-8

11. Famuyiwa OO, Edozien EM and Ukoli CO. Social, cultural and economic factors in the management of diabetes mellitus in Nigeria. Afr J Med Med Sci. 1985 Sep-Dec; 14(3-4): 145-54.

12. Famuyiwa OO. Important considerations in the care of diabetic patients in a developing country (Nigeria). Diabet Med. 1990 Dec; 7(10): 927-30. 13. American Diabetes Association. 2003. http:/ /www.diabetes.org/diabetes-statistics/cost-ofdiabetes-in-us.jsp
14. World Health Organization. How to investigate drug use in Health Facilities: selected drug use indicators. WHO/DAP/93.1. Geneva 1993.

15. University College Hospital, Ibadan. Essential Drug List and Formulary. July 2003.

16. Hogerzeil HV, Ross-Degnan D, Laing RO, Ofori-Adjei D, Santoso B, Azad CAK, Das AM, Kafle KK, Mabadeje AF. Field tests for rational drug use in twelve developing countries. Lancet 1993; 342: 1408-1410.

17. UKPDS Group, UK Prospective Diabetes Study 33: Intensive blood-glucose control with sulphonylureas or insulin compared with conventional treatment and risk of complications in patients with type 2 diabetes. Lancet 1998; 352: 837-53.

18. Adler AI, Stratton IM, Neil AW, Yudkin JS, Mathews DR, Cull CA, Wright AD, Turner RC and Holman RR. Association of systolic blood pressure with macrovascular and microvascular complications of type 2 diabetes (UKPDS 36): prospective observational study. BMJ, Aug 2000; 321: 412-419. 19. Ezenwaka CE, Akanji AO, Akanji BO, Unwin NC and Adejuwon CA. The prevalence of insulin resistance and other cardiovascular disease risk factors in healthy elderly southwestern Nigerians. Atherosclerosis 1997 Feb 10; 128 (2): 201-11.

20. Good CB. Polypharmacy in Elderly patients with Diabetes. Diabetes Spectrum. 2002; 15 (4): 240-248

21. Alebiosu CO. Antidiabetic/ Antihypertensives prescription profile in OSUTH, Sagamu and Environment. Nigerian Journal of Clinical Practice 2004; 7 (1): 15-20

22. The Heart Outcomes Prevention Evaluation Study Investigators. Effects of an Angiotensinconverting-Enzyme Inhibitor, Ramipril, on Cardiovascular Events in high-risk patients. NEJM 2000 Jan 20; 342: 145-153

23. Tuomilehto $J$ and Leiter LA. Defining the role of statins in diabetes. Br J Diabetes Vasc Dis 2005; $5: 55-62$

24. Di Napoli P, Taccardi AA, Oliver M and De Caterina R. Statins and stroke: evidence for cholesterol-independent effects. Eur Heart J 2002; 23 (24): 1908-1921. 